\title{
OS LIMITES DA UTILIZAÇÃO DE REDES SOCIAIS NA ADVOCACIA
}

Fabíola Soares de Melo, Ana Augusta Rodrigues Westin Ebaid

Universidade do Oeste Paulista, Curso de Direito, Presidente Prudente, SP. E-mail: fabiola.fah.melo@hotmail.com

\section{RESUMO}

O objetivo deste estudo foi compreender quais são os limites existentes auxiliando os operadores do direito acerca da publicidade e como ela pode ser utilizada, como por exemplo as publicações em aplicativos como Whatsapp ou Facebook.

Com os avanços da tecnologia, cada vez mais fica mais difícil saber até onde uma publicação sai da orbita de mera informação e passa a ser capitação de clientela, que é expressamente vedado pelo Código de Ética e Disciplina da OAB (Ordem dos Advogados do Brasil).

O presente artigo visa indicar tais limites existentes quando se trata da publicidade e meios tecnológicos exemplificando o que é ou não permitido.

Palavras-chave: tecnologia, publicidade, limites, OAB, aplicativos.

\section{THE LIMITS OF THE USE SOCIAL NETWORKS IN ADVOCACY}

\section{ABSTRACT}

The objective of this study was to understand the limits to the operators of the law when it comes to advertising that can be used, such as publications in applications such as Whatsapp or Facebook.

With advances in technology, it is increasingly difficult to know how far a publication goes from orbit to mere information and becomes customer capitation, which is expressly forbidden by the OAB Code of Ethics and Discipline (Brazilian Bar Association).

This article aims to indicate such limits when it comes to advertising and technological means, exemplifying what is allowed or not.

Keywords: technology, advertising, boundaries, OAB, applications. 


\section{INTRODUÇÃO}

Segundo o dicionário a palavra publicidade significa divulgação (dicionário de língua portuguesa melhoramentos, 2006), tal divulgação quando se trata de uma profissão organizada como a advocacia há a necessidade da estipulação de limites, principalmente quanto ao que pode ser utilizado e da forma permitida.

O termo publicidade tem sentido mais restrito que o vocábulo propaganda. Quando se fala em publicidade, cogita-se, apenas, de tornar público ou divulgar algo que se deseja fazer conhecido e aceito pelo público ${ }^{1}$. Já a propaganda envolve uma ação de propagar ou promover a propagação, por meio de anúncio ou mensagem, em forma de texto, música, filme ou outro meio análogo, para divulgar a qualidade de produto, serviço, atividade etc. ${ }^{2}$.

Em monografia especializada, Jerry Kirkpatrick salienta que $O$ objetivo da propaganda é vender produtos ${ }^{3}$, para, depois, observar, citando Ludwig von Mises, que $A$ propaganda de negócios deve ser atrevida e espalhafatosa ${ }^{4}$.

Nada de semelhante deve ocorrer com a divulgação dos serviços de advocacia. (MEDINA, 2016, p. 102).

Os excessos são considerados captação de clientela ou até mesmo mercantilização da profissão e são puníveis via sanções administrativas, pois a advocacia não é uma profissão antiga que merece todo respeito e consideração.

Com os avanços tecnológicos as preocupações quanto a utilização de outdoors ou até mesmo à televisão deram espaço a apreensão quanto a utilização dos novos meios tecnológicos como o Facebook, Twitter, snapchat, Whatsapp, skype, a internet no geral, pois enquanto meios como os antes utilizados podiam atingir um grupo de pessoas ou uma região a internet alcança pessoas de até outros países.

Os meios acima mencionados podem ser utilizados desde que com moderação sem visar a captação.

E-1.684/98 - PUBLICIDADE OU PROPAGANDA - DISTINÇ̃̃O - MODERAÇ̃̃O E DISCRIÇÃO - INTERNET E PLACAS INDICATIVAS - A propaganda está mais vinculada à ideia de comércio ou mercantilização para maior lucro do empresário ou comerciante. a publicidade é a informação mais discreta, sem alardes, para público menor e direito, pressupondo a existência de interesse anterior, por menor que seja. 0 advogado não vende produto, mas presta serviço especializado. Eventual anúncio de advogado, na internet ou em placas indicativas, deve ser discreto, observando a mesma moderação do veiculado em jornais e revistas especializadas que, em qualquer hipótese, não poderá ser em conjunto com outra atividade. As regras sobre a publicidade do advogado estão contidas no Código de Ética e Disciplina e na Resolução no 02/92 deste Tribunal. (OAB, 1998).

O presente trabalho possui como objetivo a analise do uso dos novos meios tecnológicos a partir de pareceres da $O A B$ e doutrina na tentativa de auxiliar os operadores do direito a reconhecer tais limites e utiliza-los a fim de evitar sanções.

\section{METODOLOGIA}

O presente estudo será desenvolvido a partir do levantamento biográfico, seguindo o método dialético-dedutivo, com o emprego de pesquisa à legislação, doutrina, pareceres do Tribunal de Ética e disciplina da OAB acerca da matéria, entre outros. 


\section{RESULTADOS}

Todas as profissões necessitam de regramentos éticos e morais que visam a igualdade entre os quais a exercem, tendo em vista que o ser humano visa seu benefício e favorecimento.

A advocacia é a profissão que dá acesso à justiça e defende interesses individuais e coletivos e juntamente com a Ordem dos Advogados do Brasil (OAB), que é o órgão responsável pelo regulamento e fiscalização surgiram os primeiros Códigos de Ética do Brasil que estipula limites e sanções a quem os excede, sendo que o atual código é proveniente do Provimento n.ㅇ 02/2015.

Antes mesmo deste provimento de 2015 já haviam regras acerca da publicidade na advocacia, mas mesmo com as mudanças significativas deste ainda há lacunas a serem preenchidas quanto a utilização da internet.

$\mathrm{O}$ art. 40 do parecer discorre acerca do assunto:

Art. 40. Os meios utilizados para a publicidade profissional hão de ser compatíveis com a diretriz estabelecida no artigo anterior, sendo vedados:

I - a veiculação da publicidade por meio de rádio, cinema e televisão;

II - o uso de outdoors, painéis luminosos ou formas assemelhadas de publicidade;

III - as inscrições em muros, paredes, veículos, elevadores ou em qualquer espaço público;

IV - a divulgação de serviços de advocacia juntamente com a de outras atividades ou a indicação de vínculos entre uns e outras;

$\mathrm{V}$ - o fornecimento de dados de contato, como endereço e telefone, em colunas ou artigos literários, culturais, acadêmicos ou jurídicos, publicados na imprensa, bem assim quando de eventual participação em programas de rádio ou televisão, ou em veiculação de matérias pela internet, sendo permitida a referência a e-mail;

VI - a utilização de mala direta, a distribuição de panfletos ou formas assemelhadas de publicidade, com o intuito de captação de clientela.

Parágrafo único. Exclusivamente para fins de identificação dos escritórios de advocacia, é permitida a utilização de placas, painéis luminosos e inscrições em suas fachadas, desde que respeitadas as diretrizes previstas no artigo 39. (BRASIL, 2015).

Existe a vedação quanto a anúncios com a utilização de fotos, valores dos honorários, exageros quanto a cor e tamanho da fonte, símbolos da $O A B$, frases que induzam a erro, ou seja, sendo vedado qualquer meio que auto promova o advogado (os excessos são considerados captação).

Porém nem tudo é proibido, é permitido que o anúncio tenha o nome completo, inscrição na $O A B$, especialidade, endereço, horários, telefone, e-mail entre outros.

A publicidade deve ser entendida apenas como divulgação e identificação de seu local de trabalho, sendo certo que temos aí um caráter de divulgação, mas sempre pautado pela sobriedade, motivo pelo qual existe vedação em utilizar fotos, valores dos serviços, tabelas, facilitação de pagamentos, bem como cargos ou funções que tenha ocupado, como a de juiz, promotor, etc. (SANCHES, 2016, p. 170).

Quanto a utilização das denominadas redes sociais é um assunto novo e polêmico, visto as lacunas no regramento existentes, facilidade do uso e o alcance que favorece a quem quer utiliza-los para benefício próprio.

Atualmente o meio que mais causa controvérsias é o Facebook pois este pode ser utilizado desde que sem finalidade econômica.

A presença de escritório de Advocacia na rede social Facebook é permitida tanto por meio da criação de "páginas" e como de "conteúdos patrocinados". A "página" do Facebook assemelha-se ao website convencional, acrescido do envio de informações, tal como ocorre com as malas diretas. Os usuários apenas recebem informações das "páginas "com as quais estabelecerem vínculo por meio do botão 
"curtir", de modo que o acesso e o envio de informações decorrem da iniciativa do próprio usuário, e não do advogado. Não viola a ética a criação de página no Facebook por escritório de Advocacia, desde que seu conteúdo se limite à divulgação de informações objetivas relativas aos advogados e à sociedade de advogados, sempre com discrição e moderação, para finalidade exclusivamente informativa e ilustrativa. Da mesma forma, não viola a ética a contratação por escritório de Advocacia de "conteúdo patrocinado", que consiste na contratação do Facebook para exibir publicidade da sociedade de advogados aos usuários. (SANCHES, 2016, p. 170).

A OAB possui pareceres dissertando acerca dos limites da utilização do Facebook pelos advogados no exercício de sua profissão:

E - 4.176/2012 - PUBLICIDADE - FACEBOOK - CRIAÇAO DE PÁGINA POR ESCRITÓRIO DE ADVOCACIA - POSSIBILIDADE - OBSERVÂNCIA DE PARÂMETROS ÉTICOS. A presença de escritório de advocacia na rede social Facebook é permitida tanto por meio da criação de "páginas" e como de "conteúdos patrocinados". A "página" do Facebook assemelha-se ao website convencional, acrescido do envio de informações, tal como ocorre com as malas-diretas. Os usuários apenas recebem informações das "páginas "com as quais estabelecerem vínculo por meio do botão "curtir", de modo que o acesso e o envio de informações decorrem da iniciativa do próprio usuário e não do advogado. Não viola a ética a criação de página no Facebook por escritório de advocacia, desde que seu conteúdo se limite à divulgação de informações objetivas relativas aos advogados e à sociedade de advogados, sempre com discrição e moderação, para finalidade exclusivamente informativa e ilustrativa. Da mesma forma, não viola a ética a contratação por escritório de advocacia de "conteúdo patrocinado" que consiste na contratação do Facebook para exibir publicidade da sociedade de advogados aos usuários. Esse tipo de publicidade apenas indica ao interessado o caminho eletrônico para página do Facebook do próprio escritório de advocacia ou ao seu website externo. Inteligência do Provimento n. 94/2000 do Conselho Federal da OAB. Prec. E-3.716/2008; E-4.013/2011 e E-4.108/2012. (OAB, 2016).

O facebook bem como as outras redes sociais podem ser utilizadas desde que atendam o regramento geral quanto publicidade, ou seja, passe informações objetivas ou com intuito de ensinar, sem fins econômicos ou de captação.

Art. 1o É permitida a publicidade informativa do advogado e da sociedade de advogados, contanto que se limite a levar ao conhecimento do público em geral, ou da clientela, em particular, dados objetivos e verdadeiros a respeito dos serviços de advocacia que se propõe a prestar, observadas as normas do Código de Ética e Disciplina e as deste Provimento. (BRASIL, 2000).

\section{CONCLUSÃO}

Para exercício da advocacia deve-se observar os limites existentes quanto a divulgação de suas atividades pois tal publicidade pode ser consideradas captação de clientela ou mercantilização da profissão o que é vedado pelo Código de Ética e Disciplina da OAB.

Os meios tecnológicos estão presentes nosso dia-dia e podem ser utilizados pelos operadores do direito desde que utilizados sabiamente, ou seja, de forma moderada e sem fins lucrativos.

Os "posts" tem grandes alcances e podem influenciar até mesmo pessoas em outros países, por isso tais meios vem tendo grande repercussão e repressão quanto os excessos. 


\section{REFERÊNCIAS}

BRASIL. Decreto lei n.ㅇ 19.408/30 de 18 de novembro de 1930. Revogado pelo Decreto n.으 11/1991, Disponível em < http://www.planalto.gov.br/ccivil_03/decreto/19301949/D19408.htm>. Acesso em: 27/03/2018).

BRASIL. Resolução n.o 02/2015 - DOU, S. 1, 04.11.2015, p.77. Conselho Federal da OAB, Disponível em: <http://www.oabsp.org.br/codigo-de-etica-2016>. Acesso em: 15/03/2018).

GONZAGA, Álvaro Azevedo, NEVES, Karina Penha, BEIJATO Jr., Roberto. Estatuto da Advocacia e Novo Código de Ética e Disciplina da OAB - Comentados, 3ạ edição. Método, 03/2017.

JUNIOR, MACEDO, Marco Antônio de. Col. OAB Nacional. Primeira fase - Ética profissional e estatuto da advocacia, vol. 10, 6a edição. Saraiva, 07/2014.

LOBO, Paulo. Comentários ao Estatuto da Advocacia e da OAB, 10ª edição. 10th edição. Editora Saraiva, 2017.

MAGRI, Wallace Ricardo. Col. OAB Nacional, 1aㅡ fase; v. 14 - Filosofia do direito, 1a Edição. Saraiva, 02/2014.

MEDINA, Paulo Roberto Gouvêa. Comentários ao Código de Ética e Disciplina da OAB. Forense, 07/2016.

MELHORAMENTOS, dicionário de língua portuguesa, Editora Melhoramentos, 2006.

OAB. V.U. do parecer e ementa do Rel. Dr. FLÁVIO PEREIRA LIMA - Rev. Dra. MARY GRUN Presidente Dr. CARLOS JOSÉ DA SILVA - 18/10/2.012.

OAB. V.U. do parecer e ementa do Rel. Dr. JOÃO TEIXEIRA GRANDE - Rev. Dr. CLODOALDO RIBEIRO MACHADO - Presidente Dr. ROBISON BARONI - 21/5/1.998.

SANCHEZ, Alessandro. Série Método de Estudo OAB - Ética Profissional e Filosofia do Direito. Método, 11/2016.

Processo n. E-4.571/2015, parecer e ementa do Rel. Pedro Paulo Wendel Gasparini. Decisão de 5/11/2015, in Boletim AASP, n. 2.973, 11 a 17 de janeiro de 2016, p. 13). 
Provimento № 94/2000 de 05 de setembro de 2000. Conselho Federal da OAB. Disponível em: <http://www.oabsp.org.br/noticias/2000/09/13/689> Acesso em: 20/03/2018). 